\title{
INTELLECTUALIZATION OF EMERGENCY CONTROL OF POWER SYSTEMS ON THE BASIS OF INCORPORATED ONTOLOGIES OF KNOWLEDGE-BASES
}

\author{
Vladimir MORKUN*, Ihor KOTOV* \\ *Faculty of Information Technology, Kryvyi Rih National University, Vitalii Matusevych Street, 11, Kryvyi Rih, 50027 Ukraine \\ morkunv@gmail..com, rioexito@gmail.com
}

received 13 November 2018, revised 14 May 2019, accepted 17 May 2019

\begin{abstract}
The research deals with improvement of methods and systems of controlling integrated power systems (IPSs) on the basis of intellectualization of decision-making support. Complex analysis of large-scale accidents at power facilities is performed, and their causes and damages are determined. There is substantiated topicality of building condition knowledge-bases as the foundation for developing decision-support systems in power engineering. The top priorities of the research include developing methods of building a knowledge base based on intensity models of control actions influencing the parameters of power system conditions and introducing the smart system into information contours of the automated dispatch control system (ADCS), as well as assessing practical results of the research. To achieve these goals, the authors apply methods of experiment planning, artificial intelligence, knowledge presentation, mathematical simulation, and mathematical statistics as well as methods of power systems studying. The basic research results include regression models of a power system sensitivity to control actions, methods of building a knowledge base based on the models of sensitivity matrices, a structure of the smart decision-support system, a scheme of introducing the decision-support system into the operating ADCS environment. The problem of building a knowledge base of the dispatch decision-support system on the basis of empirical data resulted from calculating experiments on the system diagram has been solved. The research specifies practical efficiency of the suggested approaches and developed models.
\end{abstract}

Key words: Power system, ontology, knowledge-base, decision-making support system, on-line dispatch control, factorial model

\section{INTRODUCTION}

Analysis of development and operation of the Ukrainian and foreign power systems allows deducing incremental integration, complexity and hierarchical pattern of their structure and control algorithms. Consequently, the total number of breakdowns and accidents is growing, as well as the salvage values. Ukrenergo's press service informs about the following (Avariynost $v$ energosisteme Ukrainyi za god vyrosla vdvoye, 2015): 'The stateowned company "Ukrenergo", the operator of the integrated power system of Ukraine, is warning about possible critical situations in Ukraine's power system because of escalation of breakdowns of basic equipment in main, interstate and distributing electric grids of the country. As reported by the national power company, in 2014, the accident rate doubled as compared to that of 2013'.

The article studies a wide range of domestic and foreign sources dealing with accidents at large technological objects including electric power companies (Besanger et al., 2013; International Atomic Energy Agency, 2018; Report of the Unified Energy System of Russia on investigating the accident on May 25, 2005; Roy R. et al., 2015; Sibikin et al., 2017). There are some largescale accidents worth mentioning considering their content, damage and personnel's wrong actions.

- The accident at Chagino 500-kV substation of the OJSC 'Mosenergo' mains caused interruption of power supply of socially significant objects in Moscow, Tula, Kaluga, Riazan and Smolensk regions of Russia. The damage made 1,600 mln RUB. The personnel failed to prevent massive power cut of
$110 \mathrm{kV}$ and $220 \mathrm{kV}$ lines. Mikhailov-Chagino $500 \mathrm{kV}$ line of the double-extended mode was not provided. The personnel's actions to provide and restore acceptable voltage in the southern part of the Moscow power system were not efficient;

- As a result of the power cut in Rio-de-Janeiro and São Paulo (Brazil), the oceanic coast of Rio-de-Janeiro with $10 \mathrm{mln}$ residents was completely cut off power. The defect was not identified in due time and accurately;

- In the USA and Mexico, two reactors of the NPP were cut off and more than $10 \mathrm{mln}$ people were left without electricity. The accident was caused by a company worker's error while organizing works at the substation;

- The massive power cut took place in the capital of Argentina, Buenos-Aires. The capital centre, the presidential palace, the Congress and government buildings were powered off. The personnel spent a lot of time on clarifying all the details of the accident and coordinating their actions;

- Munich and Moosburg (Germany) were powered off when the underground and electric trains did not work. About 500 thousand people suffered from the most large-scale accident in the last 20 years. It took a lot of time to eliminate the accident;

- The started-up 500 MW reactor of the French NPP 'St. Lawrence' exploded and about $50 \mathrm{~kg}$ of liquid nuclear fuel escaped because of the operator's inattention as the fuel channel was loaded inappropriately; 
- There was leakage of water of the intermediate circuit and detonation of the relief valve at Unit 2 of Zaporizhzhia NPP (Ukraine). The unplanned idle time of the unit caused serious losses because of reduced generation of electricity. The operators allowed temperatures of independent circuits to increase.

Besides, let us provide some generalized data for analysing malfunctions at electric power plants, thermal and electric grids, power generating and supplying companies and power systems of the national power company Ukrenergo (Accident rates of Ukrainian power engineering facilities in 2005 . The industry data document, 2005). According to the data given, at the Ukrainian power engineering objects, the number of breakdowns caused by 'the personnel's wrong actions' has increased by $25 \%$ making $6.7 \%$ of their total number, those due to 'wrong actions of the supervising personnel, service and laboratory workers' - by $6.6 \%$ making $17.8 \%$ of their total number, those due to 'influence of unauthorized people and organizations' $-52.5 \%$ making $6.8 \%$ of their total number. In general, violations of technological processes due to the personnel's wrong actions (the human error factor) make $31.3 \%$ in total according to the classifying features.

The considered factors greatly reduce the level of power security of industrial entities and the state as a whole. The term 'power security' is based on the notions of an accident, an emergency and a crisis (Reliability standards for the bulk electric systems of North America. NERC, 2007; Maintenance of power stations and grids. Rules, 2003).

In the situations described above, specific responsibility lies on the shoulders of the operating and dispatch personnel (ODP) of power facilities. Duties of ODP can be described as a chain of controlling decisions based on operational/on-line data. Decisions are made either under the standard operational mode of the power system or in case of emergency. When the standard operational mode is on, the personnel do not feel any psychological pressure, people's decisions are balanced as they have enough time to assess a situation and make a decision. In case of emergency, when the power system's stability is essential, the personnel are to take responsibility and not always make evident decisions within the shortest possible time under the pressure of taking care of material assets and people's lives.

Analysis has revealed that emergencies and accidents at large industrial plants cause great losses both in men and material. Improvement of automated control systems is accompanied by growing complexity of industrial complexes (Morkun et al., 2014). Therefore, the amount of accident damages is increasing rather than decreasing. The authors systematized and analysed the latest and most relevant factual materials on accidents and emergencies in aviation, surface and water transport, industry and power engineering. It is evident to deduce from the research the necessity of reasonable combination of automatic and automated control means as well as corresponding engineering complexes. The increased number of the latest accidents indicates expedience and urgency of human factor consideration. Automated control in power systems is one of the priorities. Special responsibility rests upon the dispatch personnel. They are unable to respond to emergencies appropriately because of psycho-physiological limitations and high emotional overload. Consequently, the problem of on-line control over such a complicated object as a power system should be solved by means of automation of smart decisionsupport means. Therefore, researches aimed at developing and implementing smart decision-support systems are of great scientific and practical significance (Status Review of Regulatory Ap- proaches to Smart Electricity Grids, 2011; Tolshakov, 2014).

Assuming that the ODP is considered a component of the ADCS of power systems, the problem of intellectualization of the ADCS emergency functions is extremely acute while managing power systems in emergency operation (Bao et al., 2018; Heliodore et al., 2014; Morkun et al., 2014).

Results' analysis and the problem topicality allow formulating the following key goals of the research:

- analysing and generalizing causes of accidents in power systems and the role of dispatch personnel in emergency response;

- substantiating the topicality of the problem of intellectualization of the ACDS emergency functions of power systems;

- specifying the problems of developing and implementing digital substations;

- building a regression model of the sensitivity matrix of the electric grid to control actions;

- checking adequacy of applied methods and obtained regression models;

- developing incorporated knowledge ontologies to manage integrated power system conditions in emergency operation;

- determining a scheme and points for implementing an expert system into the ADCS complex of the integrated power system;

- demonstrating application of incorporated knowledge ontologies to power system management;

- testing the obtained results through clear and understandable examples.

\section{ANALYSIS OF RESEARCH AND PUBLICATIONS}

Many international scientists are investigating the theory, methods and implementation of smart power grids, their results being significant. The following works are worth mentioning (Baldinger et al., 2010; Benysek et al., 2011; Council of European Energy Regulators, CEER Status Review of Regulatory Approaches to Smart Electricity Grids, Brussels, 2011; Hashmi et al., 2011; Joas et al., 2018; Sobczyński et al., 2015; Swora 2011; Woszczyk, 2009). Besides, the works by Robert W. Gee (Vice President, Development and Partner Relations, The Electricity Innovation Institute), Jeffrey R. Pillon (Michigan Public Service Commission), Terry Surles (Director, Technology Systems Division, California Energy Commission), Marek Woszczyk (Vice President Energy Regulatory Office in Poland) should be considered as well.

Among the Ukrainian specialists dealing with problems of power system intellectualization, one should mention Bashlykov, Liubarskiy, Khoroshevskiy, Tolshakov, and so on.

Modern development of power systems and economic conditions of their functioning raise strict demands to their management (Bevrani H. et al., 2017; Morkun et al., 2015), the basic of which are the following:

- operational choice of generating sources;

- integration of heterogeneous power sources in the power system;

- automated elimination of accident consequences;

- efficient and reliable rendering of market ancillary services;

- resistance to security threats;

- efficient use of production assets.

Solution of the given problems is within global trends implying transformation of conventional power systems into smart power 
systems (SPS) which are a version of 'smart grids' (Babu, 2018; Buchholz et al., 2014; Lund et al., 2017). The SPS is mostly noted for the ability to make independent decisions, self-diagnostics and recovery. Wide area management systems (WAMS) of power parameters, digital devices of relay protection and automation, advanced metering infrastructure (AMI), integrated user-side service/duel service interface (DSI), and so on are good examples of
SPS services. The smart approach to preventing accidents comprises three basic components - monitoring, security assessment and security enhancement or control. Transition from conventional power systems to smart ones is given in (Technology roadmap. SmartGrid, 2011; Vingerhoets et al., 2016) and illustrated in Fig. 1.
Past

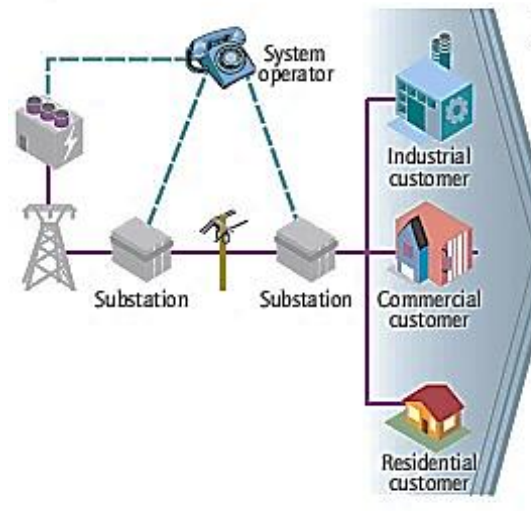

Present Transmission Distribution Transmission
control centre

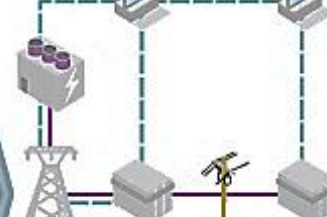

Substation
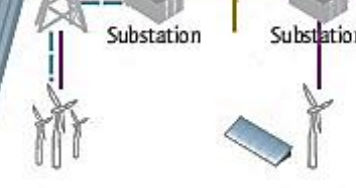

Fig. 1. Transition of power system architecture into smart one

Solution of these tasks is obligatory for controlling power system conditions (Lund et al., 2017; Morkun et al., 2018; Panasetskiy et al., 2014). To detect near-accident conditions, there is accomplished smart monitoring and security assessment based on data collection and classification of power system conditions. Data collection is performed by SCADA, which detects a set of disturbed parameters. Smart monitoring and analysis are possible solutions of the problem as, according to Morkun et al. (2014) and Negnevitskiy et al. (2013), most near-accident conditions causing system accidents are unique and there is no single algorithm of detecting these conditions.

It can be said that the concept of smart power systems and resulting smart power system management are a long-term trend in the development of large power engineering systems and their ADCS. This concept is based on the term 'intellectualization', which means making decisions by hardware items or decisionmakers on the basis of accumulated and structured knowledge (professional experience).

The concept of intellectualization of power systems along with its basic principles and ways of realization is presented on a system-defined and reasonable basis by Morkun et al. (2015) and Volkova et al. (2011). The main argument in favour of intellectualization of power systems and automated emergency systems is the fact that 'potential economic and social damages because of threats and possible breakdowns of power system elements within the whole power grid are comparable to damages caused by natural disasters (hurricanes, floods, etc.) or even surpass them' (Volkova et al., 2011).

Basic functions of SPS and smart systems are accomplished through a set of digital devices and IT elements of the SPS. One of the basic SPS units is a digital substation (Berdnikov et al., 2012; Morkun et al., 2015; Morzhin et al., 2013). A digital substation is a highly automated substation in which almost all processes of data exchange between its elements and external systems and those of controlling the substation operation are controlled digitally as prescribed by the International Electrotechnical Commission - IEC 61850 ('Systems and communication networks in substations'). Meanwhile, both initial equipment of digital substations and components of information-technological and controlling systems are functionally and structurally oriented on supporting digital data exchange. Fig. 2 reveals an integrated system of a digital substation as part of SmartGrid and the group of 'smart' buildings and facilities.

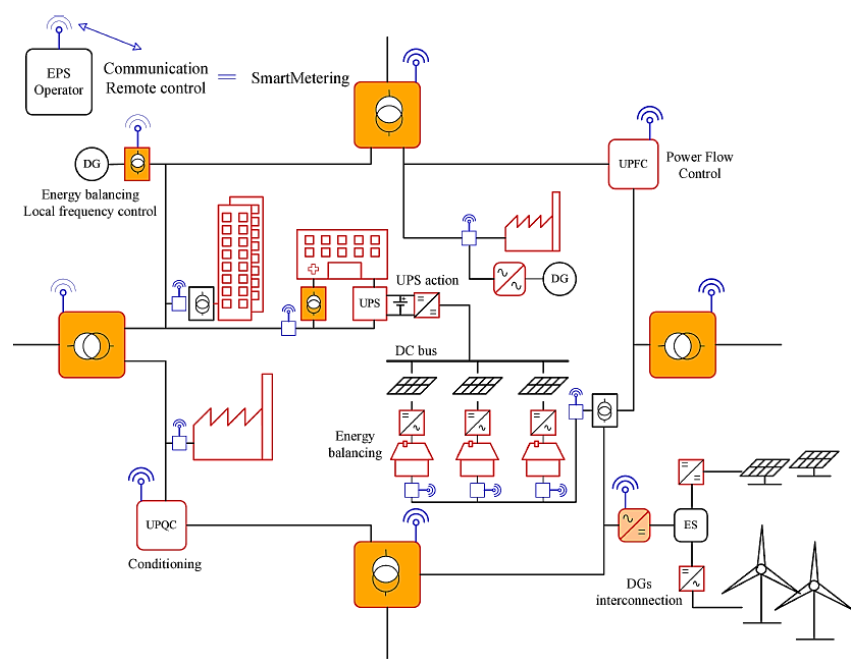

Fig. 2. SmartGrid with SmartMetering \& SmartBuilding technology (The figure is borrowed from the paper by Benysek, Kazmierkowski, Popczyk J., Strzelecki R., 2011)

Introduction of digital technologies and intellectualization of the ADCS of power systems have a considerable positive effect. Yet, intellectualization of power systems faces serious problems of updating certain power facilities. Additional problems arise from 
social and economic conditions, namely, scarce funding, personnel's low qualification, outdated regulatory and instructive bases, established traditions of work organization, and so on, for example, indicates that 'most similar systems are restricted to functions of data acquisition, pre-processing and visualization. Generalizing assessments of current situations and decision-making resulting in corresponding plans of further actions remain the responsibility of the personnel as before'. Analysis of the potential of current smart power facilities and systems (Dronova, 2016) allows concluding that 'systems of personnel's support in decision making are reasonable to be used as new components integrated into the automated control system of the given power equipment'.

Following the analysis of many research works, we can draw a conclusion that creating smart power systems and facilities is quite promising, yet at present, there are some objective problems of realizing these projects.

Some smart hardware and software complexes-advisers can be used as the most balanced and efficient solutions to the problem of emergency control system automation within the automated dispatch management system of power systems. They are noted for relatively low initial investment, absence of auxiliary requirements to the current data infrastructure for installation, high technical and economic efficiency. Dispatch advisers are hardware and software packages of decision-support systems (DSS) based on artificial intelligence. There is available wide national and international experience of creating DSS for controlling power systems (Kuno et al., 2012).

Thus, comparative analysis of available scientific and engineering decisions in the sphere of automated emergency control systems allows for the conclusion about topicality and necessity of developing smart DSS and their introduction as part of the ADMS of power systems.

\section{RESEARCH OBJECTIVES}

The conducted analysis enables formulating the task of creating a support system of the power system dispatcher's managerial decisions. Basic functions performed by DSS should be guiding. The whole variety of the functions can be presented as two basic directions of DSS actions:

- identifying an emergency;

- developing and applying controlling impacts.

The problem of identifying an emergency should be solved by methods of recognition (classification). In this case, on the basis of a training sample (when disturbance, the character of transition and severity estimates are known), a function of measured parameters of the mode and disturbance distributing conditions according to severity is built (Bao et al., 2015).

The second subtask is associated with finding the most effective points of applying control actions (power system units) and the structure of the actions to enhance the system's stable functioning. This problem can be solved by means of methods of experiment design, taxonomy, and so on.

After creating the DSS and determining the technology of introducing it into the current online data management complex, its knowledge base should be replenished. For this purpose, experiments of the dispatcher's impacts on the grid scheme of the power system are planned and conducted. The knowledge-base is filled with images of emergency conditions and formalisms of the dispatcher's decisions accompanied by estimates of control actions in the form of response matrices. The procedure of DSS functioning is based on developing a scenario of a software package operation in the environment of the total system of automated dispatch management of power systems. According to the operation scenario, efficiency of the DSS is assessed and corresponding indices are chosen and grounded.

When using the methods of factorial design, a range of changes of control dispatch actions is determined in various units of the power system and their influence on the system's condition is assessed. Multiple calculations of the transient process guided by the factorial design followed by data processing should result in forming a dependency of a response on the control action vector.

The relevant value of significance of separate impacts is reflected in corresponding factors, their impact on the response being assessed by setting them equal to zero. Considering reciprocal influence of substations in the transient condition, they can be combined into classes according to the influence quantity.

The presented plan provides the following research tasks:

- determination of mode parameters characterizing the current condition of the power system;

- design and conduction of experiments to assess the influence of control actions on modes of characteristic controlled units of the power system;

- assessment of adequacy of models and formation of influence response functions of control actions on conditions of controlled units of the power system;

- formation of empirical response matrices of the power system as to control actions on the basis of response functions;

- formation of professional ontologies based on empirical knowledge-bases of condition characteristics of controlled units of the power system;

- development of the integrated scheme of the DSS accompanied by ADMS means based on incorporated professional ontologies.

\section{RESEARCH RESULTS}

To solve the research problems, the general methodology of the research should be expressed as follows. Solution of the problem of providing high-quality control of the power system condition is based on the fact that bulk of the input data on the system scheme and condition under study is processed in advance and asynchronously. Therefore, the data can be considered a knowledge base. Control functions are formed according to detected application points and adjustment of control actions. The control-action adjustment is conditioned by methods of multiple planned designed experiments and built regression models. After statistic adequacy tests of the resulted models, they can be used as new knowledge about the control over the condition of a certain dispatch control object. The research applies general methods of building architecture of smart systems and automated dispatch control systems. There are used methods of experiment planning, mathematical statistics, the theory of sets, the theory of electrical circuits and formal languages. Adequacy of obtained results is checked and harmonized with the activity of dispatch personnel. For this reason, the research methods are relevant and can be applicable to the professional field chosen. The problem of determining a subset of controlling units of the power system involves transformation of $Y=F(X)(X$ is the initial n-dimensional space of factors, $Y$ is a new m-dimensional space, $n>m$ ). Dimensionality in the space $Y$ should be minimal, yet sufficient for distinguish- 
ing this class-taxon. Next, the problem of choosing optimal control actions is solved by the methods of the experiment design theory.

Parameters characterizing a standard condition, a disturbance and a grid structure are chosen as independent factors. An adaptive criterion of the system condition quality (the amount of cut load and generating capacities, reconfiguration of the grid scheme) are used as control actions.

To study a particular emergency, a set of calculation experiments is conducted to determine optimal amounts of control actions and obtain a satisfactory mode. After processing all experiment results, there are obtained polynomial dependencies characterizing the standard (near-accident) condition, the grid structure and disturbance (independent impacts) and optimal control action adjustment (Gluskin et al., 2009):

$u_{i}=K_{i 0}+\sum_{j=1}^{n} K_{i j} X_{j}+\sum_{j} \sum_{l} K_{i j l} X_{j} X_{l}+\cdots$. (1)

The considered methods provide the basis for the expert DSS of the power system dispatcher. The research is conducted on the operational guidance materials of the dispatch control office of the National Dispatch Centre (NDC) of the Integrated Power System (IPS) of the NPC 'Ukrenergo'.

The knowledge base is formed by combining dispatch instructions to control active power interchange and new knowledge based on experiment data of mode tests.

To assess condition parameters of the studied cluster of the power grid, a model of equations of the established condition is used in the form of power balance in the units:

$\dot{\omega}_{s k}(\dot{U})=\dot{S}_{k}^{*}-\dot{Y}_{k k} \dot{U}_{k} \dot{U}_{k}^{*}-\sum_{j=1, j \neq k}^{N} \dot{Y}_{k j} \dot{U}_{j} \dot{U}_{k}^{*}$,

where: $\dot{\omega}_{s k}(\dot{U})$ - is an unbalance function in the unit $k, \dot{S}_{k}^{*}$ - is a conjugate complex of the $k$-th unit power, $\dot{Y}_{k k}-$ is intrinsic conduction of the $k$-th unit, $\dot{U}_{k}$ - is a voltage complex of the $k$-th unit, $\dot{U}_{k}^{*}$ - is a conjugate voltage complex of the $k$-th unit, $\dot{Y}_{k j}$ - is reciprocal conduction of the $k$-th and $j$-th units, $N$ - is the number of units in the studied cluster of the grid.

To make model (2) applicable in the software package, the variables are separated and presented by real numbers in polar coordinates:

$\omega_{P k}(U)=P_{k}-g_{k k} U_{k}^{2}-U_{k} \sum_{j=1, j \neq k}^{N} U_{j}\left(g_{k j} \cos \delta_{k j}-\right.$ $\left.b_{k j} \sin \delta_{k j}\right),(3)$

$\omega_{Q k}(U)=Q_{k}-b_{k k} U_{k}^{2}-U_{k} \sum_{j=1, j \neq k}^{N} U_{j}\left(b_{k j} \cos \delta_{k j}+\right.$ $\left.g_{k j} \sin \delta_{k j}\right),(4)$

where: $\delta_{k j}=\delta_{k}-\delta_{j}, \delta_{k}, \delta_{j}$ - are phase angles of vectors of the voltage modules of the $k$-th and $j$-th units.

The experiments are aimed at finding characteristics of intensities of interconnection of condition controlled parameters of a dispatch control object, in particular, active power flow and factors of dispatch control actions as to the electric grid (for example, by varying capacities of generating units and transformation factors of coupling transformers of 750/330-kV nominal voltage).

The resulted set of models present a binary relation defined on the subsets of controlling and controlled parameters:

$$
N^{\prime} \beta P^{\prime}=\begin{array}{ccc}
\left\{\left(n_{1}^{\prime}, p_{1}^{\prime}\right),\right. & \ldots, & \left(n_{1}^{\prime}, p_{k}^{\prime}\right), \\
\left(n_{2}^{\prime}, p_{1}^{\prime}\right), & \ldots, & \left(n_{2}^{\prime}, p_{k}^{\prime}\right), \\
\ldots, & \ldots, & \ldots \\
\left(n_{m}^{\prime}, p_{1}^{\prime}\right), & \ldots, & \left.\left(n_{m}^{\prime}, p_{k}^{\prime}\right)\right\}
\end{array}
$$

where: $N^{\prime} \beta P^{\prime}$ - is a binary relation defined on the subsets of controlling $N^{\prime}=\left\{n^{\prime} \mid i=1, m\right\}$ and controlled $P^{\prime}=$ $\left\{p^{\prime} \mid j=1, k\right\}$ - parameters.

Interconnection models of subsets of controlling and controlled parameters are presented in the form of a response matrix:

$\left|\begin{array}{ccc}\beta_{11} & \ldots & \beta_{1 k} \\ \beta_{21} & \ldots & \beta_{2 k} \\ \cdots & \beta_{i j} & \ldots \\ \beta_{m 1} & \cdots & \beta_{m k}\end{array}\right|,(6)$

where: $\beta_{i j}=\left(n_{i}, p_{j}\right)$ - is an impact ratio, $n_{i}, p_{j}$ - are controlling and controlled parameters of a dispatch control object. The ratio $\beta_{i j}$ - is realized as standard regression models:

$\bar{Y}=$

$b_{0}+\sum_{i=1}^{k} b_{i} X_{i}+\sum_{i=1}^{k} \sum_{j=1}^{k} b_{i j} X_{i} X_{j}+$

$\sum_{i=1}^{k} \ldots \sum_{n=1}^{k} b_{i \ldots n} X_{i \ldots n}+\sum_{i=1}^{k} b_{i i} X_{i}^{2},(7)$

where: $b_{0}, b_{i}, b_{i j}, b_{i \ldots n}, b_{i i}$ - are estimates of regression factors determined by experiment results.

After statistical study of the obtained models to assess their adequacy, they are used as new knowledge about controlling a dispatch control object's condition. Application of this kind of knowledge as elements of the response matrix allows rejecting full-scale calculations of the set mode of the power system while assessing the required actions and designing dispatch decisions. This fact facilitates the DSS switching over to an on-line mode.

The network map of the following classes of nominal voltage ( $750 \mathrm{kV}, 500 \mathrm{kV}, 330 \mathrm{kV}, 220 \mathrm{kV}$ ) is used in the function of the rated one. The studied line has 156 units and 210 branches, ten of which are parallel. There are 26 autotransformers and 184 power lines. 9 autotransformers are characterized by complex values of transformation factors. In 42 units, values of voltage modules are fixed and variation limits of the available reactive power are set. To compensate the charge capacity of $750 \mathrm{kV}$ ETL (electric transmission line), reactors are switched on in 13 units of the network map.

Parameters of the mode taken as the initial one correspond to the autumn consumption schedule and time of the day from 4 p.m. to 5 p.m.

While forming the experimental part of the knowledge-base, the research focuses on the dispatch interchange control at South-Ukraine Nuclear Power Plant-Vinnitsa through controlling the power of some large generating units and complex transformation factors of coupling autotransformers. The impact of reactive power flow in the function of an important factor of dispatch control is not studied because of invariance of tested methods in terms of the content of the models.

Tab. 1 presents input parameters of the experiments for controlled units of the power system (a linear response model is chosen in a first approximation).

Calculation and analytical experiments result in sets of response functions for control actions in the given units. Obtained regression models adequately describe the influence of active power flow at South-Ukraine Nuclear Power Plant-Vinnitsa and can be used to form dispatch control actions.

After checking the value of regression factors, the following response function is obtained:

$Y=1409.32+81.40 X_{2}+49.69 X_{3}+142.98 X_{4}$. (8)

True factors of the model can be verified by control computa- 
tion of the steady-state condition. Let us choose the values of parameters at the zero level. This variant provides an evident result while using the model $P=1557.99 \mathrm{MW}$. The calculated steady-state condition for the given conditions result in the flow value of $P=1558.50 \mathrm{MW}$ corresponding to the relative error of $0.03 \%$.

Tab. 1. Levels of experiment factors and variation intervals

\begin{tabular}{|c|c|c|c|c|c|c|c|}
\hline \multirow[t]{2}{*}{ \# } & \multirow[t]{2}{*}{ Units } & \multirow[b]{2}{*}{ 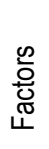 } & \multicolumn{3}{|c|}{ Factor levels } & \multirow[b]{2}{*}{ 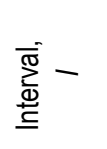 } & \multirow{2}{*}{ 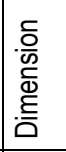 } \\
\hline & & & - & 0 & +1 & & \\
\hline 1 & 2 & 3 & 4 & 5 & 6 & 7 & 8 \\
\hline 1 & $\begin{array}{l}\text { Kakhovka } \\
\text { MSDS }\end{array}$ & $\mathrm{X} 1$ & -413.41 & -327.41 & -241.41 & 86.00 & MVA \\
\hline 2 & $\begin{array}{l}\text { Kaniv } \\
\text { HPP }\end{array}$ & $X 2$ & -220.48 & -99.32 & 21.82 & 121.15 & MVA \\
\hline 3 & $\begin{array}{l}\text { Kyiv } \\
\text { TPP6 }\end{array}$ & X3 & -68.60 & 68.16 & 204.91 & 136.76 & MVA \\
\hline 4 & $\begin{array}{l}\text { Dniester } \\
\text { HPP }\end{array}$ & X4 & 59.91 & 239.64 & 419.38 & 179.73 & MVA \\
\hline
\end{tabular}

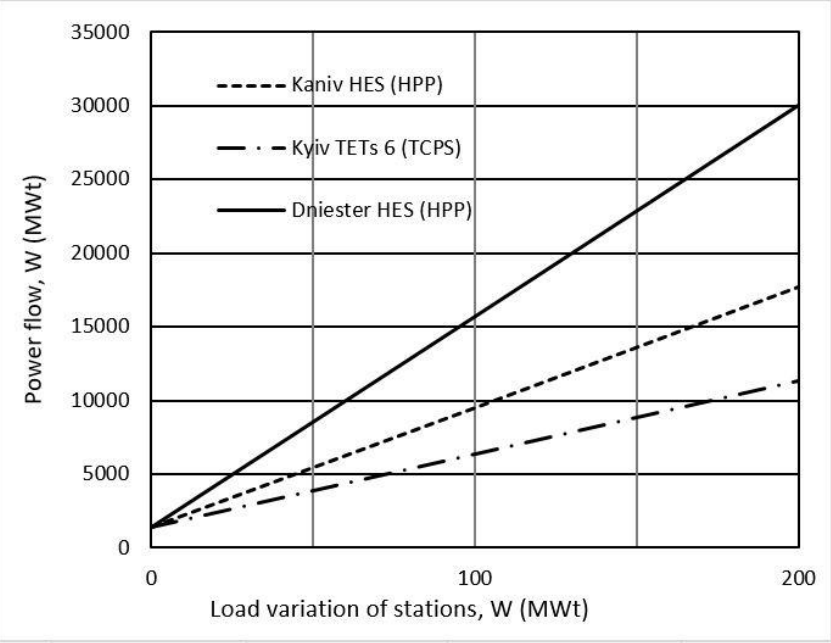

Fig. 3. Experiment data of the impact of generating stations on power flow at South-Ukraine Nuclear Power Plant-Vinnitsa
When fixing some regression parameters (4) at the zero level, illustrations of the impact of generating stations on power flow are obtained (Fig. 3).

To verify the adequacy of the applied mathematical apparatus in building regression models, Shapiro-Wilk $W$-test is used (Hanusz Z., 2016).

While analysing the conditions of power systems, full-scale tests are replaced by model calculations, so dispersion of parameters can be assessed in a simplified form:

$\sigma^{2}(y)=\sum_{i=1}^{n} b_{i}^{2} \sigma^{2}\left(X_{i}^{H}\right)+\sum_{i=1}^{N} \sum_{j=1}^{N} b_{i j}^{2} \sigma^{2}\left(X_{i}^{H}\right) \sigma^{2}\left(X_{j}^{H}\right)$.

(9)

Experiment results reveal that $\bar{Y}=1409.32$.

In this case,

$$
\sum_{i=1}^{16}\left(Y_{i}-\bar{Y}\right)^{2}=472864.11
$$

and the value of adequacy dispersion is

$\sigma^{2}=\frac{472864.11}{15}=31524.27$.

As the $n$-sample is an even number, the difference number is $k=16 / 2=8$.

According to table data, we obtain

$b=\sum_{i=1}^{8} a_{n k} \Delta k=672.40$.

In this case, the $W$-test is

$W=\frac{b^{2}}{(n-1) \sigma^{2}}=\frac{452121.76}{15 * 31524.27}=0.956$.

As $W>W_{0.05}$, the mathematical apparatus is adequate to solve problems and its application does not cause any false interpretation of the object domain.

To introduce the developed DSS, it is necessary to solve two important problems:

- determination of possible places to install the system and its functional orientation at installation points;

- creation of software-to-software interface of the system on a real-time basis.

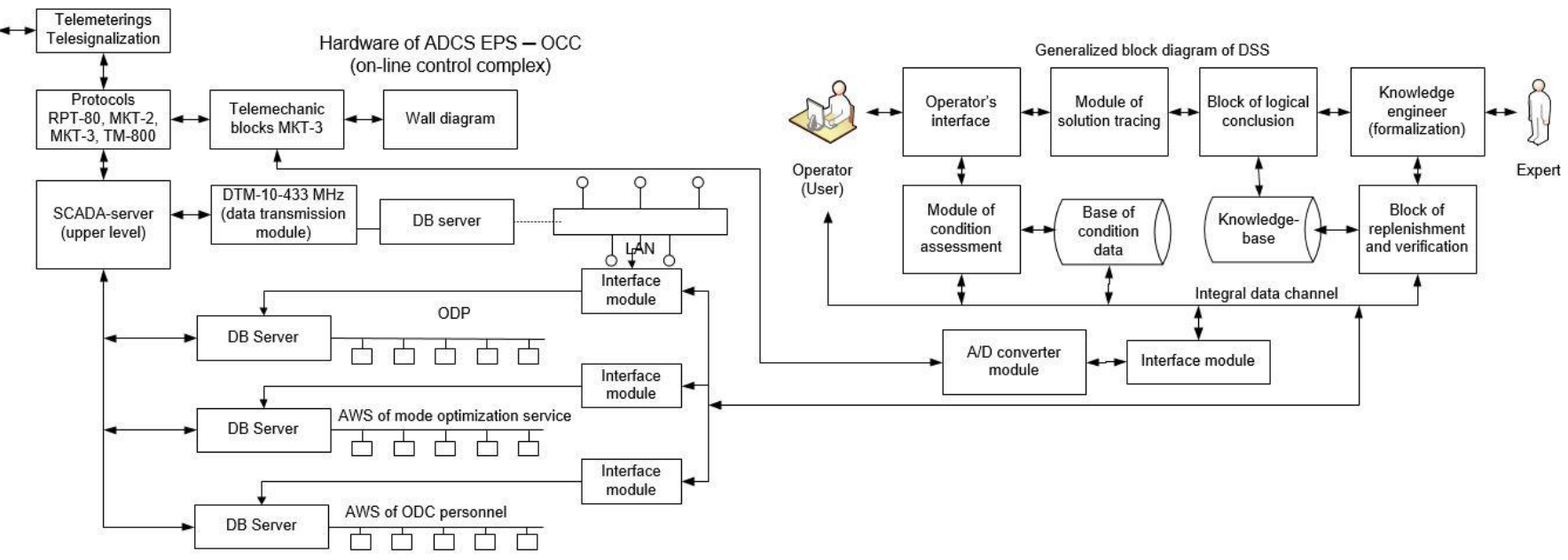

Fig. 4. Suggested structural scheme of integration of the DSS into the ADCS to monitor power system conditions 
The indicated problems can be solved after considering the structure and principles of functioning software and hardware means of the ADCS of a particular power facility. The dispatch control tasks are realized by means of data collection, transmission, processing and display as well as and CASE-tools enhancing the solution of control tasks and data connection with hierarchical control levels. The control levels are equipped with universal computers to exchange on-line information with a set of hardware means of the integrated dispatch control (IDC). The overall description of the ADCS hardware is provided in Morkun et al. (2015), Peng et al. (2018), and PKP Energetyka (2018). The following scheme of DSS incorporation into the ADCS of power systems is suggested (Fig. 4).

Possible installation points of the created expert system can be defined in the following way.

With regard to hardware means of data processing:

- a local network of IBM-compatible PCs with cross-machine exchange of on-line data including an automated work place connected through a file-server computer with the central computer to access hardware means, programs and the data bank;

- a circuit for cross-machine exchange of on-line data along with automated formation of daily records, process-statistical and economic-planning data based on teleprocessing;

- within the circuit of data acquisition, display and processing, the use of the mentioned hardware means of transmission of on-line telemetry data.

With regard to subsystems of mathematical support:

- the environment of software means of on-line data and computation complexes;

- tasks of dispatching on-line control and statistical data processing;

- the subsystem of recording and analysing efficiency of previous daily conditions;

- software support of an on-line data base;

- applied mathematical support associated with restriction of power flows across separate sections and lines;

- tasks of current improvement of HPP modes by computing means;

- tasks of current improvement in terms of transformation factors and loads;

- mathematical support of process-statistical data processing. With regard to the dispatch and technological personnel:

- a dispatcher's automated work place;

- a process engineer's automated work place based on the local computer network;

- an automated work place of an engineer of the mode optimization service;

- an automated work place of an engineer of the mathematical support development and operation service.

\section{TESTING}

To test the suggested method, a clear and understandable example is provided.

Considering instructive and empirical data, the DSS is built to control power flow at the interchange of South-Ukraine Nuclear Power Plant-Vinnitsa (SUNPP-Vinnitsa). A knowledge base provides the foundation to build ontologies of concepts, facts, products and databases.
The DSS controls power flows for a current condition of the grid. When the value exceeds the standardized limits, the system generates control actions on the basis of sensitivity matrices. Next, the products from the rule base are used to form pieces of advice for a dispatcher to provide directions, rates of controlling the condition or changing the power system diagram.

The obtained designs provided the basis for testing emergency trainings (TET) of the dispatch personnel. The calculating models of Ukraine's integrated power system were used as control objects. Two equal groups of dispatchers of equal qualification and work experience took part in the trainings:

- group 1 (2 people per shift) without using the DSS;

- group 2 (2 people per shift) using the DSS.

The dispatchers' actions were assessed by experts on a scale from one to five according to the methods suggested in (Merkurev G.V., 2002).

The initial conditions of the training include:

- the controlled object is the interchange of SUNPP-Vinnitsa including the following high-voltage (HV) lines: $750 \mathrm{kV} \mathrm{HV}$-line of SUNPP-Vinnitsia, 330 kV HV-line of Konotop-Nizhyn, 330 kV HV-line of KremHPP-Cherkasy, 330 kV HV-line of SUNPPPobuzhzhia, 330 kV HV-line of Tryhaty-Adzhalyk, 330 kV HVline of Homel-Chernihiv, 330 kV HV-line of Mozyr-ChNPP;

- the operation mode is standard;

- the operation mode with the Interconnected Power System (IPS) of East European countries is parallel;

- the power flow value along the $750 \mathrm{kV} \mathrm{HV}$-line of SUNPPVinnitsia is $1300 \mathrm{MW}$;

- the admissible power flow in the interchange for the set conditions is $3600 \mathrm{MW}$;

- the fixed current power flow along the intersystem transit (interchange) is $3640 \mathrm{MW}$;

- the fixed exceeded limit of the intersystem power flow is 40 MW;

- the partial failure or insufficient efficiency of the emergency control automatics is fixed;

- there is a failure of synchronous operation of Ukraine's IPS and the East European one.

The training is aimed at eliminating the exceeded intersystem power flow within 1-2 hours according to the instruction. Otherwise, the power system dispatcher has to divide asynchronously operating parts of the integrated power system.

The training strategy implies fulfilling the training task and forming the following assessment parameters of the dispatchers' activity (Merkurev G.V., 2002):

- $q_{1}$ is correct timely actions;

- $q_{2}$ is unfulfilled actions;

- $q_{3}$ is incorrect actions;

- $q_{4}$ is behind-schedule actions;

- $q_{5}$ is actions performed earlier than necessary;

- $q_{6}$ is unnecessary actions;

- $\quad q_{7}$ is non-optimal actions.

The results of the conducted trainings are in Tab. 2 .

During the training, on the basis of the DSS knowledge base and the sensitivity matrices, the required controlling actions are determined:

- the total controlling action is $12.5 \mathrm{MW}$;

- the controlling action of the Dniester HPP is $11.36 \mathrm{MW}$ :

- the controlling action of Kaniv HPP is $1.14 \mathrm{MW}$.

After conducting independent emergency trainings (both with and without using the DSS) and obtaining the parameters $q_{1}-q_{7}$, 
the following expert professional and psychological characteristics of dispatchers are obtained:

- $\alpha$ is expertise;

- $\rho$ is reliability;

- $\quad \beta$ is proficiency level;

- $\quad \gamma$ is psychological stability;

- $\delta$ is immediacy and accuracy;

- $\quad \lambda$ is the intensity of natural failures of dispatcher shifts;

- $Y$ is the evaluation of contingent damage due to power undersupply and its reduced quality.

Tab. 2. Final results of the dispatch personnel's testing emergency trainings

\begin{tabular}{|l|l|}
\hline Indices without using of the DSS & Indices with the DSS \\
\hline$q_{1}=4.80$ & $q_{1}=4.96$ \\
$q_{2}=1.0$ & $q_{2}=1.0$ \\
$q_{3}=0.5$ & $q_{3}=0.42$ \\
$q_{4}=2.2$ & $q_{4}=1.94$ \\
$q_{5}=0.2$ & $q_{5}=0.2$ \\
$q_{6}=0.2$ & $q_{6}=0.12$ \\
$q_{7}=1.8$ & $q_{7}=0.55$ \\
\hline$\alpha=4.8 / 11.0=0.43$ & $\alpha=4.96 / 9.19=0.54$ \\
$\rho=1-4.4 / 11.0=0.6$ & $\rho=1-3.68 / 11.03=0.67$ \\
$\beta=1-3 / 11.0=0.76$ & $\beta=1-2.36 / 11.03=0.79$ \\
$\gamma=1-0,4 / 11.0=0.964$ & $\gamma=1-0,32 / 11.03=0.971$ \\
$\delta=1-4.3 / 11.0=0.61$ & $\delta=1-2.49 / 11.03=0.77$ \\
\hline$\lambda=0.048$, failures/month & $\lambda=0.042$, failures/month \\
\hline$Y=\alpha_{1} P_{1} 2.8$ & $Y=\alpha_{1} P_{1} 0.92$ \\
\hline
\end{tabular}

Generalization of the training results enables conclusions of the DSS efficient application to dispatch control of the IPS in emergency, concerning the following:

- the personnel's professional and psychological characteristics have improved due to the DSS;

- intensity of dispatcher shifts' failures has reduced;

- the contingent damage due to power undersupply has decreased.

\section{CONCLUDING REMARKS}

The research is an original investigation into intellectualization of power facilities control. The manuscript is original research as a specific approach to building a knowledge base is suggested. The knowledge base is based on the dispatchers' instructions for accident response. At the same time, regression dependencies of the power system's sensitivity to controlling dispatcher actions are included into production rules. The method of incorporating various forms of knowledge representation within a single smart system is developed to build the knowledge base. The study formulates an integrated approach to incorporating professional knowledge to build smart decision-support systems and automated control of complex-structured objects. It differs by simultaneous implication of integrated forms of knowledge representation comprising concepts, facts and production rules. All the levels of the knowledge structure are described by means of a single model of ontologies enabling us to unify representation and processing of knowledge of power grid conditions.

The mathematical apparatus of presenting and using ontologies is improved and noted for being based on fundamental forms of representing knowledge irrespective of the subject areas.

Thus, we can draw the following conclusions:

- there are determined condition parameters characterizing the current condition of the IPS, power flows in certain power system lines being such parameters;

- a set of experiments has been planned and conducted, the influence of control actions on condition parameters characterizing the controlled areas of the IPS being determined;

- the obtained ratios of impacts have confirmed numerical adequacy of the regression models of response functions to generate control actions on the power system parameters;

- the sensitivity matrices as ratios between the values of controlling and controlled parameters of the power system condition have been built;

- there are suggested new ontologies of knowledge bases of the dispatch control over the power system conditions in the form of sensitivity matrices based on factor condition models considering the interrelation of controlling and controlled parameters of the power system condition;

- a scheme of integrating the DSS into the ADCS is offered to monitor the IPS condition on the basis of the empiric knowledge base of condition characteristics of the power system;

- practical testing of the obtained results through a clear and understandable example is conducted and the elaborated theoretical models are confirmed.

\section{REFERENCES}

1. Accident rates doubled in Ukraine's power system (2015) (in Russian), retrieved from: https://economics.unian.net/energetics/ 1073586-avariynost-v-energosisteme-ukrainyi-za-god-vyirosla-vdvoe. $\mathrm{html}-30.04 .2015$.

2. Accident rates of Ukrainian power engineering facilities in 2005. The industry data document (2005). Association of power enterprises 'Industry Reserve and Investment Fund of Power Engineering Development' (in Ukrainian). Enerhia, Kyiv.

3. Babu N. R. (2018), Smart Grid Systems: Modeling and Control, CRC Press, Apple Academic Press, 290.

4. Baldinger F., Jansen T., Riet M., Volberda F. (2010), Nobody knows the future of Smart Grid, therefore separate the essential in the secondary system - Developments in Power System Protection, the 10th IET International Conference (DPSP), 29 March - 1 April 2010, Manchester, UK.

5. Bao Y., Guo Ch., Zhang J., Wu J., Pang S., Zhang Zh. (2018), Impact analysis of human factors on power system operation reliability, J. Mod. Power Syst. Clean Energy, Springer Verlag, Berlin, 6(1), 27-39.

6. Bao Y., Li Z., Wen D., Guo Ch. (2015), Development and design of dispatcher training simulation evaluation system based on IDAC, Conference: 2015 IEEE PES Asia-Pacific Power and Energy Engineering Conference (APPEEC), 1-5.

7. Benysek G., Kazmierkowski M.P., Popczyk J., Strzelecki R. (2011), Power electronic systems as a crucial part of Smart Grid infrastructure - a survey, Bulletin of the Polish Academy of Sciences: Technical Sciences, Power electronics, 59(4), 455-473.

8. Berdnikov R.N., Morzhin Yu.I., Shakaryan Yu.G. (2012), Basic principles of the smart power engineering system of Russia with the active and adaptive grid. Power of the Unified Grid(in Russian), Energiya Yedinoy Seti, 4, 4-11. 
9. Besanger Y., Eremia M., Voropai N. (2013), Major grid blackouts: Analysis, classification, and prevention, Handbook of Electrical Power System Dynamics: Modeling, Stability, and Control, New Jersey: Wiley - IEEE Press, 789-863.

10. Bevrani H., Hiyama T. (2017), Intelligent Automatic Generation Control, CRC Press, Taylor \& Francis Group, 308

11. Buchholz B.M., Styczynski Z. (2014), Smart Grids - Fundamentals and Technologies in Electricity Networks, Springer Verlag, Berlin, 396.

12. Dronova Yu.V. (2016), Risks of implementing smart grids into power complexes of the Russian Federation regions. Economy and Management: Problems, Solutions, Management Problems (in Russian), $2(6), 77-83$

13. Gluskin I.Z., lofev B.I.. Meklin A.A., Chekalovec L.N. (2009), Emergency automation in power systems (in Russian), Moscow: Znak, 568.

14. Hanusz Z., Tarasinska J., Zielinski W. (2016), Shapiro-Wilk test with known mean, REVSTAT Statistical Journal, 14(1), 89-100.

15. Hashmi H.M., Hanninen S., Maki K. (2011), Survey of Smart Grid Concepts, Architectures and Technological Demonstrations Worldwide, IEEE PES Conference, Innovative Smart Grid Technologies (ISGT), Medellin, Oct.

16. Heliodore F., Poullain S., Boussaad I., Nakib A. (2014), Methodology for management of power system emergency situations, PGMOCOPl'14 Conference on optimization \& practices in industry, 3.

17. International Atomic Energy Agency (2018), Nuclear Power Plant Operating Experience, IAEA, Vienna, 53.

18. Joas F., Oswald K., Wido Witecka (2018), RAP: Report on the Polish Power System. Version 2.0 Study commissioned by Agora Energiewende, Mercator Foundation and the European Climate Foundation, 48

19. Kuno M.Ya., Kondratev A.N., Chalisov Yu.I., Malyishev A.V., Morozovich R.B., Sulimov V.A. (2012), Dispatch Adviser for eliminating overloads in the power system. Technical and Software Means of Automation Systems (in Russian), 5(34), 34-37.

20. Lund H., Østergaard P.A., Connolly D., Mathiesen B.V. (2017), Smart energy and smart energy systems, Energy, 137, 556-565.

21. Merkurev G.V. (2002), Operative and dispatch control of power systems. Methodological Guide. Teaching Guide (in Russian). Edition of the Energy Training Center, 116

22. Morkun V., Morkun N., Tron V., Hryshchenko S. (2018), Synthesis of robust controllers for the control systems of technological units as iron ore processing plants, Eastern European Journal of Enterprise Technologies, 1(2-91), 37-47.

23. Morkun V., Tcvirkun S. (2014), Investigation of methods of fuzzy clustering for determining ore types, Metallurgical and Mining Industry, 5, 11-14.

24. Morkun V., Morkun N., Pikilnyak A. (2015), Adaptive control system of ore beneficiation process based on Kaczmarz projection algorithm, Metallurgical and Mining Industry, 2, 35-38.

25. Morkun V., Morkun N., Pikilnyak A. (2014), The adaptive control for intensity of ultrasonic influence on iron ore pulp, Metallurgical and Mining Industry, 6, 8-11.

26. Morkun V., Morkun N., Tron V. (2015), Model synthesis of nonlinear nonstationary dynamical systems in concentrating production using Volterra kernel transformation, Metallurgical and Mining Industry, 10, 6-9.

27. Morkun V., Morkun N., Tron V. (2015), Formalization and frequency analysis of robust control of ore beneficiation technological processes under parametric uncertainty, Metallurgical and Mining Industry, 5, 7-11

28. Morzhin Yu.l., Popov S.G. (2013), Digital substation. Concept, implementation technology (in Russian). Unified Grid Power, 5, 4-19.
29. Negnevitsky M., Tomin N., Panasetsky D., Kurbatsky V. (2013), Intelligent Approach for Preventing Large-Scale Emergencies in Electric Power Systems, Proceedings from IEEE International Conference on Electric Power Engineering PowerTech, Grenoble, France, 16-20 June, 1-6.

30. Report of the Unified Energy System of Russia on investigating the accident on May 25, 2005 (2005) (in Russian). RAO «UES of Russia», appointed by order, 331, Moscow, 48.

31. Panasetskiy D.A., Tomin N.V., Kurbatskiy V.G., Voropay N.I., Efimov D.N. (2014), Smart emergency control of power system modes (in Russian). The Institute of Control Problems named after V.A. Trapeznikov of the Russian Academy of Sciences, Moscow, 4770-4782.

32. Peng Zh., Na Liu, Jing Ch., Qi-feng Zh., Man-man Lin (2018), A New Dispatch Control Integration System of the Smart Grid Based on the Regional Network Centralized Protected Mode, Journal of Clean Energy Technologies, 6(4), 324-332.

33. PKP Energetyka (2018), Implementation of the centralised system of controlling traffic in the SCADA / ADMS power and traction system. Engineering standards for NC facilities. Standardisation and Data Quality (in Polish), Warszawa, 33.

34. Reliability standards for the bulk electric systems of North America. NERC (2007), Retrieved from: http://www.nerc.com - 18.08.2017.

35. Roy R., Vijayakumar A., Nair R. (2015), A Study on Electrical Accidents and Safety Measures, International Journal of Latest Trends in Engineering and Technology (IJLTET), 5(2), 147-154.

36. Sibikin Yu.D. (2017), Maintenance of electrical equipment of power stations and substations: teaching guide for students of higher educational institutions (in Russian). Moscow: Berlin, Direkt-Media, 447.

37. Sobczyński D., Balawejder M. (2015) Participation of consumers in Smart Grid development (in Polish), Scientific Journals of Rzesziw University of Technology, Series: Electrotechnics, RUTJEE , 34(4), $5-13$

38. Status Review of Regulatory Approaches to Smart Electricity Grids (2011), Council of European Energy Regulators, CEER, Brussels, $37-40$.

39. Swora M. (2011), Smart Grids after the Third Liberalization Package: Current Developments and Future Challenges for Regulatory Policy in the Electricity Sector, Yearbook of Antitrust and Regulatory Studies, 4(4), 9-22.

40. Maintenance of power plants and grids. Rules (2003) (in Ukrainian), DP "NTUKC" AsEIEnergo, 599.

41. Technology roadmap. Smart Grids (2011), International Energy Agency, OECD/IEA, 49.

42. Tolshakov, A.V. (2014), Smart Grid: development, practice, problems (in Russian). Enerhonadzor, 1(53).

43. Vingerhoets P., Chebbo M., Hatziargyriou N. (2016), The Digital Energy System 4.0, European technology platform Smartgrids, 72.

44. Volkova I.O., Okorokov V.R., Okorokov R.V., Kobets B.B. (2011), Concept of smart power systems and its potential in the Russian power engineering (in Russian). The Russian Academy of Sciences. The Institute of National Economy Forecasting. The Open Seminar "Economic Problems of the Power Complex", INP RAN, Moscow.

45. Woszczyk M. (2009), The Smart Grid and Smart Metering Polish Perspective, ERRA Chairmen Meeting, Istanbul, 17 November, 19. 